RESEARCH HIGHLIGHTS

accumulation through its own, carefully timed, self destruction.

So, Rape and Kirschner have identified what they suggest is the 'self-perpetuating oscillator' that pushes the cell cycle through its phases (see figure). Accumulation of cyclin-A-CDK1 and cyclin-B-CDK1 promotes entry into mitosis and activation of $\mathrm{APC} / \mathrm{C}^{\mathrm{CDC} 20}$, which, in turn, induces degradation of the mitotic cyclins and mitotic exit (a). $\mathrm{APC} / \mathrm{C}$ acquires the $\mathrm{CDH} 1$ adaptor in G1 and degrades the remaining $\mathrm{APC} / \mathrm{C}^{\mathrm{CDH} H}$ substrates (b), which facilitates UBCH10 autoubiquitylation and degradation (c). Cyclin A then re-accumulates (d) and completely inactivates $\mathrm{APC} / \mathrm{C}^{\mathrm{CDH}}(\mathrm{e})$, thereby initiating entry into $S$ phase and allowing further mitotic-cyclin accumulation (f). So, as the saying goes: what goes around comes around...

Lesley Cunliffe

(2) References and links ORIGINAL RESEARCH PAPER Rape, M. \& Kirschner, M. W. Autonomous regulation of the anaphase-promoting complex couples mitosis to S-phase entry. Nature 432, 588-595 (2004) FURTHER READING

Reed, S. I. Ratchets and clocks: the cell cycle, ubiquitylation and protein turnover Nature Rev. Mol. Cell Biol. 4, 855-864 (2003)

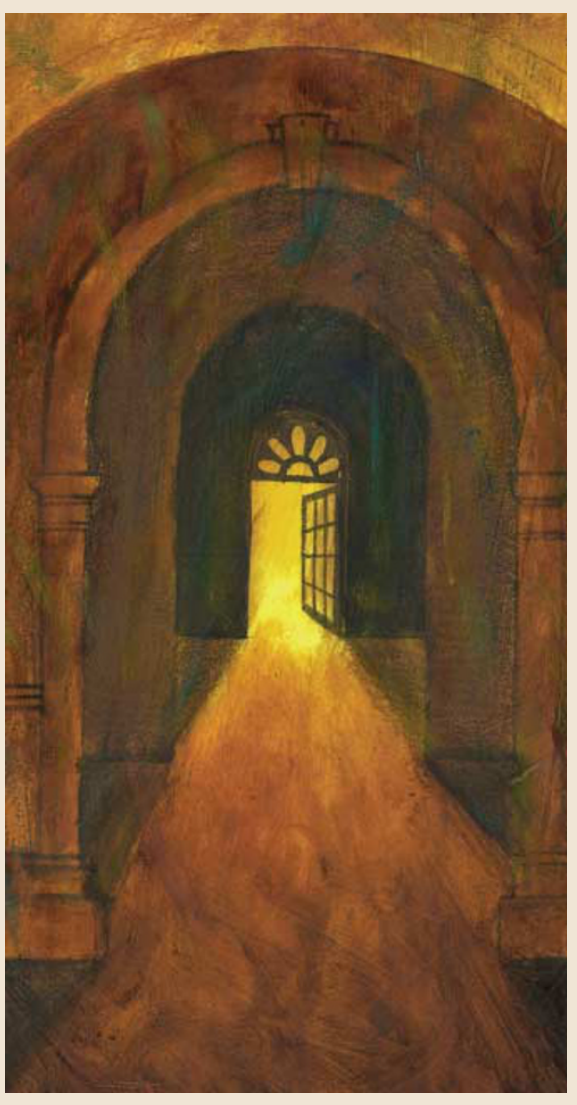

TRANSCRIPTION

\section{Nuclear actin muscles in}

The physiological significance of actin in the nucleus has been questioned in the past. However, several recent studies have implicated actin in RNA polymerase (Pol) II transcription. And, two papers now report that actin is also required for Pol I and Pol III transcription.

Given that actin usually works in conjunction with myosin motor proteins, and that a type of myosin I - NMI — has been shown to be involved in Pol II transcription, Ingrid Grummt and colleagues investigated the role of both actin and NMI in Pol I transcription, as reported in Nature Cell Biology. They found that depleting or inhibiting actin or NMI decreased Pol I transcription in vivo, thereby indicating that both proteins are involved in this process.

In vitro Pol I transcription assays with either naked DNA or pre-assembled chromatin required both actin and NMI. By contrast, the formation of short, trinucleotide transcripts in a so-called 'abortive transcription assay' was unaffected by treatment with anti-actin antibodies. So, actin and NMI have a direct role in ribosomal DNA transcription, rather than enhancing transcription through a chromatinremodelling effect, and actin seems to function in a post-initiation event.

Immunoprecipitation experiments showed that both actin and NMI associated with the Pol I machinery. The fraction of Pol I that is associated with TIFIA, a basal transcription-initiation factor, is transcription competent. Interestingly, whereas actin was associated with the bulk Pol I population, NMI bound only to TIFIA-containing Pol I. In addition, the association of NMI with TIFIA-containing Pol I depended on the phosphorylation of TIFIA on Ser649 - a modification that is known to be required for transcriptioninitiation-complex formation.

Using chromatin immunoprecipitation (ChIP) assays, Grummt and co-workers showed that NMI associated with the rDNA promoter but not the coding region, whereas actin associated with both the promoter and the coding region. Together, these data indicated that actin and NMI have distinct roles in Pol I transcription - NMI functions in the assembly of Pol I transcription-initiation complexes, whereas actin functions in a post-initiation event, possibly transcription elongation.

Reporting in Genes \& Development, Nouria Hernandez and colleagues found that highly purified Pol III contains $\beta$-actin. Interestingly, two of the Pol III subunits that were found to interact with $\beta$-actin are common to all three RNA polymerases. ChIP analysis indicated that $\beta$-actin localized close to

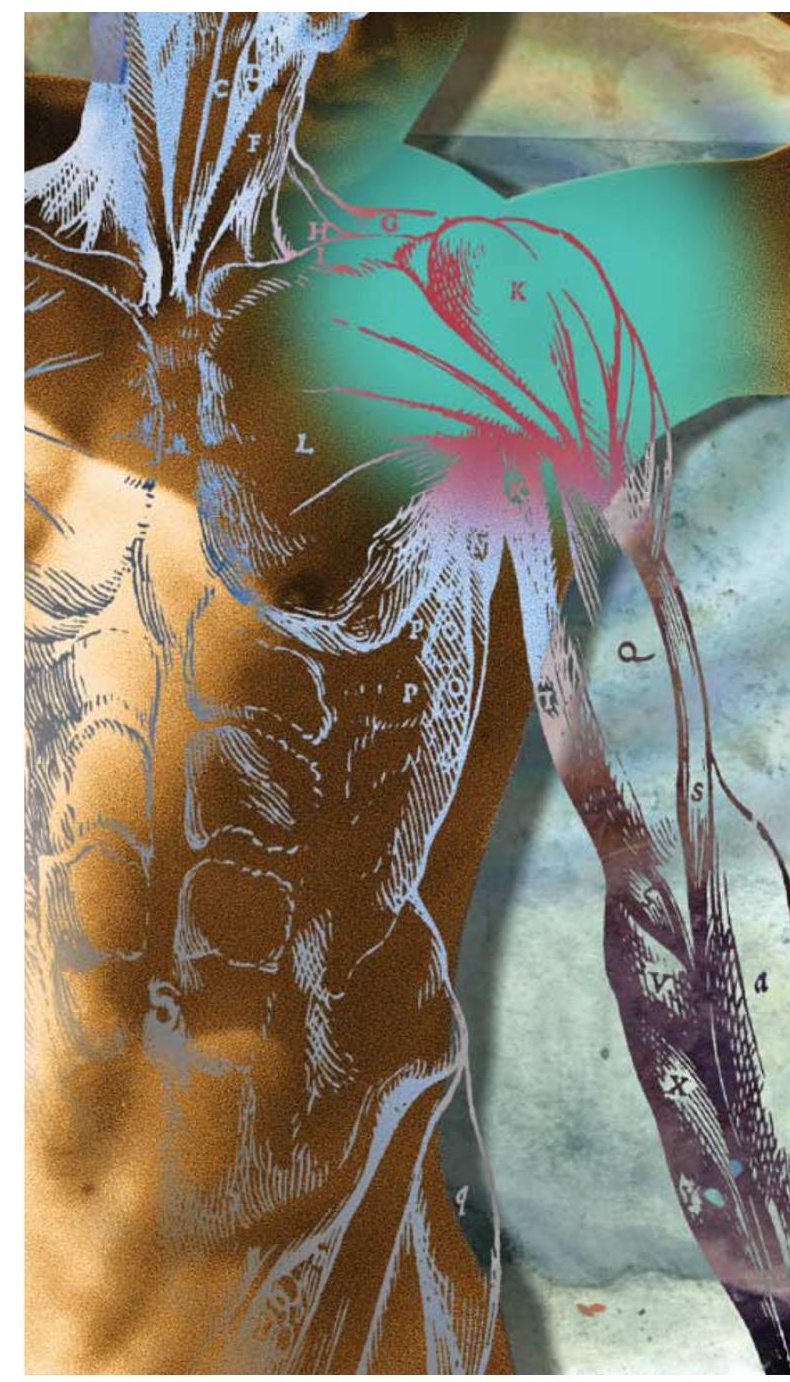

the promoter region of an actively transcribed U6 gene in vivo, which indicates that $\beta$-actin might function in the transcription process.

Immunoprecipitated Pol III from cells that had been treated with a DNA-damaging agent lacked $\beta$-actin. Also, both Pol III and $\beta$-actin were largely dissociated from the U6 promoter in these cells, and Pol III that was purified from treated cells was inactive in an in vitro transcription assay. However, transcription could be reconstituted by adding $\beta$-actin and the CK2 kinase (which phosphorylates Pol III) to inactive Pol III.

So, the two studies clearly show a direct role for actin in Pol I and Pol III transcription and, given previous findings, the two groups propose that actin is required for the function of all three RNA polymerases.

\section{(i) References and links}

Arianne Heinrichs

ORIGINAL RESEARCH PAPERS Philomonenko, V. V. et al. Nuclear actin and myosin I are required for RNA polymerase I transcription. Nature Cell Biol. 6, 1165-1172 (2004) | Hu, P. et al. A role for $\beta$-actin in RNA polymerase III transcription. Genes Dev. 1 Dec 2004 (doi:10.1101/gad.1250804)

FURTHER READING Bettinger, B. et al. Actin up in the nucleus. Nature Rev. Mol. Cell Biol. 5, 410-415 (2004) 